\title{
Comparative Evaluation of Frictional forces between different Archwire-bracket Combinations
}

\author{
Dr Vinit Singh,' Dr Swati Acharya,2 Dr Satyabrata Patnaik,3 Dr Smruti Bhusan Nanda4 \\ 'Orthodontist, ${ }^{2}$ Senior Lecturer, 4 Reader, Dept of Orthodontics, \\ 3Senior lecturer, Dept of Oral Surgery \\ Institute of Dental Sciences, Bhubaneswar, India
}

Correspondence: Dr Swati Acharya; email: swati.acharya.tmdc@gmail.com

\section{ABSTRACT}

Introduction: During sliding mechanics, frictional resistance is an important counterforce to orthodontic tooth movement; which must be controlled to allow application of light continuous forces.

Objective: To investigate static and kinetic frictional resistance between three orthodontic brackets: ceramic, self-ligating, and stainless steel, and three $0.019 \times 0.025$ " archwires: stainless steel, nickel-titanium, titanium-molybdenum.

Materials \& Method: The in vitro study compared the effects of stainless steel, nickel-titanium, and beta-titanium archwires on frictional forces of three orthodontic bracket systems: ceramic, self-ligating, and stainless steel brackets. All brackets had 0.022" slots, and the wires were $0.019 \times 0.025$ ". Friction was evaluated in a simulated half-arch fixed appliance on a testing machine. The static and kinetic friction data were analyzed with 1-way analysis of variance (ANOVA) and post-hoc Duncan multiple range test.

Result: Self-ligating (Damon) brackets generated significantly lower static and kinetic frictional forces than stainless steel (Gemini) and ceramic brackets (Clarity). Among the archwire materials, Beta-titanium showed the maximum amount of frictional force and stainless steel archwires had the lowest frictional force.

Conclusion: The static and kinetic frictional force for stainless steel bracket was lowest in every combination of wire.

Key words: Beta-titanium wire, frictional resistance, kinetic friction, self-ligating, static friction

\section{INTRODUCTION}

The increasing use of sliding mechanics in orthodontics has lead to considerable research interest in friction. ${ }^{1}$ Friction is an important factor in sliding mechanics; friction is encountered during retraction of teeth into extraction area, active torque, leveling and alignment when the archwire must slide through bracket slots and tubes. ${ }^{2,3,4}$ During sliding mechanics, the biologic tissue responds and tooth movement occurs only when forces applied exceed the friction on bracket wire interface.

Initially, the static friction between archwire and bracket must be overcome to initiate tooth movement, then after, while the tooth is moving, dynamic friction occurs as the archwire in the direction of the applied force, as it is guided through the bracket slots. ${ }^{5}$ So the present study was conducted to evaluate the static and kinetic frictional forces of different type of brackets (stainless steel, ceramic and self-ligating) with different archwire systems (stainless steel, NiTi and BetaTitanium or TMA) and to compare the static and kinetic frictional forces between the different archwire and bracket combination.

\section{MATERIALS AND METHOD}

The present study was conducted in the Department of Orthodontics, Himachal Dental College, Sundarnagar, India. The study was performed to evaluate the friction between different types of orthodontic brackets and orthodontic wires.

All brackets used in the study were preadjusted 0.022" slots with following varieties: stainless steel (Gemini, 3M Unitek), ceramic (Clarity, 3M Unitek), and self-ligating (Damon SLII, Ormco). The wires used in the study were $0.019 \times 0.025$ " with following types: Stainless Steel (SS), Nickel-Titanium (Ni-Ti) and Titanium-Molybdenum alloy (TMA). Rectangular wires were chosen for this study because they offer control in all three planes of space. A universal testing machine (Instron, Model-5848) was used for the study. A custom-made jig of $0.019 \times 0.025$ " stainless steel straight wire was prepared. Four edgewise brackets were bonded to a rigid metal base plate of $8 \mathrm{~mm}$ intervals with $16 \mathrm{~mm}$ space for a movable bracket at the center. The evaluation was done according to the test protocol described by Tidy ${ }^{6}$ as shown in Figure 1 and 2. The archwire was secured with wire ligatures. The bracket slots 


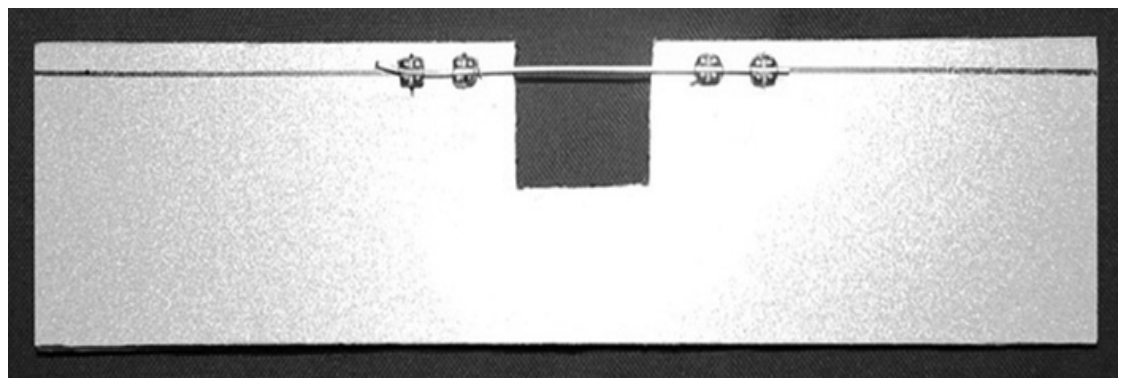

Fig 1: Bracket-wire combination setup

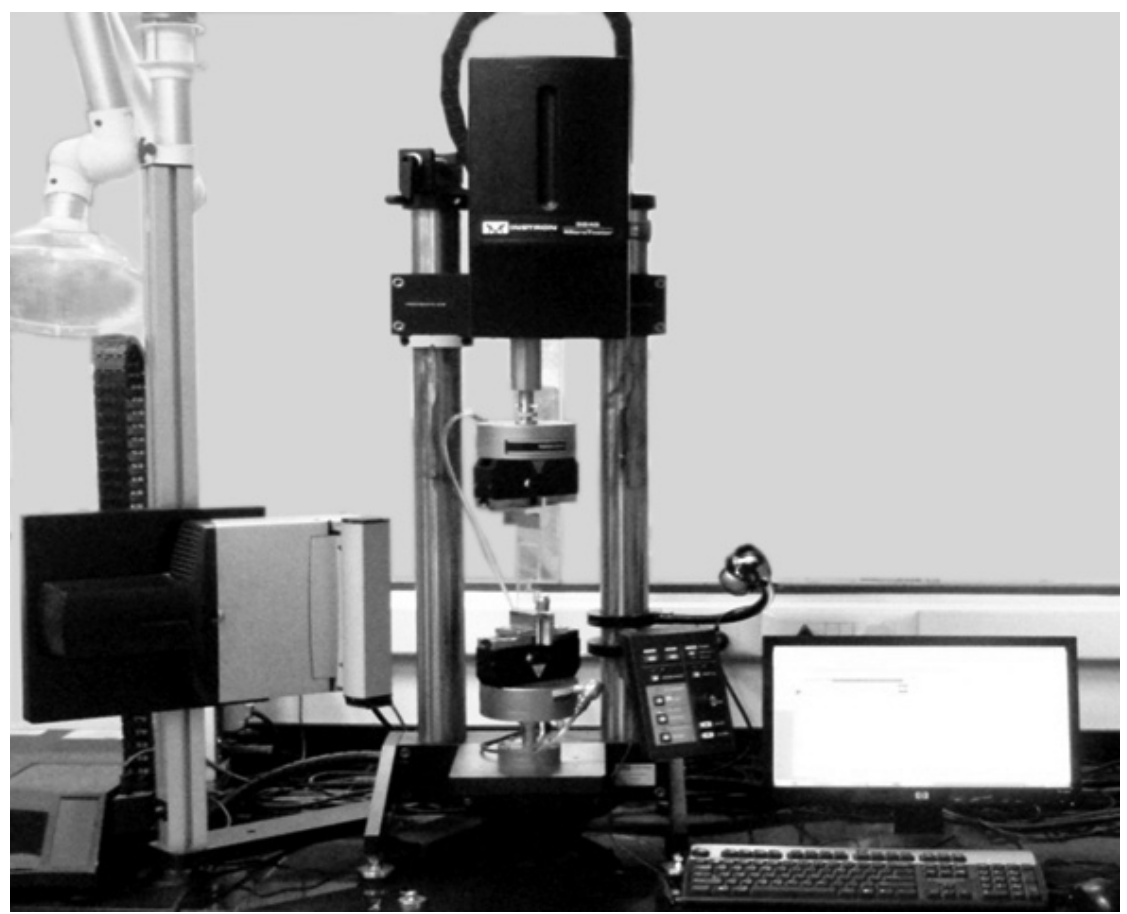

Fig 2: Universal Testing Machine (Instron 5848)

were set up in the way, archwires of stainless steel, nickeltitanium and TMA were used turn by turn.

A total of 180 bracket-archwire readings were taken for the study. Each bracket was tested only once and each wire specimen was drawn through one bracket only to eliminate the influence of wear. Thus for each bracket-archwire combination, the test was carried out ten times, and the average was recorded. The ligature on the movable bracket was at first fully tightened, then slackened to permit free sliding. The movable bracket was fitted with a $10 \mathrm{~mm}$ power arm from which weight could be hung to represent the single equivalent force acting at the center to represent the distance from the slot to the Center of resistance of a typical canine tooth. All tests were conducted under dry conditions with an Instron (Model 5848) testing machine with the crosshead moving downward at a speed of $2 \mathrm{~mm} / \mathrm{min}$. The movable bracket was suspended from the load cell of testing machine while the metal base plate moved downward with the crosshead on which it was mounted. In each test, the bracket was moved a distance of not less than $2.5 \mathrm{~mm}$ across the central space and the load cell reading was recorded on the chart paper. Weight suspended from the power arm provided the load of $100 \mathrm{gm}$. The load cell readings represented the clinical force of retraction that would be applied to the tooth, part of which would be lost in friction while the remainder was transmitted to the tooth root. At the start of each test, a trial run with no load on the power arm was done to check if the wire ligature was bending on the archwire.

A load-deflection graph was plotted on a computer during each test, where the $x$-axis represented the bracket movement in millimeters and the $y$-axis recorded the load in Newton. The initial peak of the graph was taken as static friction, and kinetic friction was determined by averaging five reading on the $y$-axis at fixed intervals. 


\section{RESULT}

Descriptive statistics including mean and standard deviation of the static and kinetic frictional forces were calculated for all types of bracket-archwire combination. The values of static and kinetic frictional forces are shown in Table 1, 2 and 3. One-way analysis of variance (ANOVA) and Post hoc test was done to evaluate the difference between the means of different brackets with different archwires as shown in Table 4, 5 and 6.

Table 1: Descriptive statistics of static and kinetic frictional forces for stainless steel bracket

\begin{tabular}{|c|c|c|c|c|c|c|c|c|c|}
\hline Frictional force & Archwire & $\mathbf{N}$ & Mean & SD & SEM & Min & $\operatorname{Max}$ & F-value & $p$-value \\
\hline \multirow{3}{*}{ Static peak (gm) } & SS & 20 & 157.85 & 103.42 & 23.13 & 38.75 & 450.71 & \multirow{3}{*}{11.25} & \multirow{3}{*}{$0.000 *$} \\
\hline & NiTi & 20 & 246.00 & 117.51 & 26.28 & 47.93 & 455.81 & & \\
\hline & TMA & 20 & 321.76 & 106.69 & 23.86 & 153.97 & 462.94 & & \\
\hline \multirow{3}{*}{ Avg. Kinetic friction (gm) } & SS & 20 & 138.35 & 95.92 & 21.45 & 72.40 & 494.55 & \multirow{3}{*}{12.73} & \multirow{3}{*}{$0.000 *$} \\
\hline & NiTi & 20 & 239.26 & 101.61 & 22.72 & 108.33 & 489.46 & & \\
\hline & TMA & 20 & 280.63 & 75.63 & 16.91 & 92.28 & 404.82 & & \\
\hline
\end{tabular}

One way ANOVA statistics, *significant at $p<0.05$

Table 2: Descriptive statistics of static and kinetic frictional forces for ceramic bracket

\begin{tabular}{|c|c|c|c|c|c|c|c|c|c|}
\hline Frictional force & Archwire & $\mathbf{N}$ & Mean & SD & SEM & Min & $\operatorname{Max}$ & F-value & $p$-value \\
\hline \multirow{3}{*}{ Static peak (gm) } & SS & 20 & 212.40 & 144.00 & 32.20 & 138.68 & 537.38 & \multirow{3}{*}{12.407} & \multirow{3}{*}{$0.000^{*}$} \\
\hline & $\mathrm{NiTi}$ & 20 & 295.25 & 83.36 & 18.64 & 41.81 & 427.25 & & \\
\hline & TMA & 20 & 365.56 & 27.15 & 6.07 & 305.91 & 383.41 & & \\
\hline \multirow{3}{*}{ Avg. Kinetic friction (gm) } & SS & 20 & 208.11 & 124.84 & 27.92 & 137.25 & 450.95 & \multirow{3}{*}{11.618} & \multirow{3}{*}{$0.000^{*}$} \\
\hline & NiTi & 20 & 284.35 & 24.70 & 5.52 & 203.94 & 302.04 & & \\
\hline & TMA & 20 & 321.98 & 34.46 & 7.70 & 298.16 & 392.58 & & \\
\hline
\end{tabular}

One way ANOVA statistics, *significant at $p<0.05$

Table 3: Descriptive statistics of static and kinetic frictional forces self-ligating bracket

\begin{tabular}{|c|c|c|c|c|c|c|c|c|c|}
\hline Frictional force & Archwire & $\mathbf{N}$ & Mean & SD & SEM & Min & Max & F-value & $p$-value \\
\hline \multirow{3}{*}{ Static peak (gm) } & SS & 20 & 135.00 & 72.45 & 16.20 & 32.63 & 299.79 & \multirow{3}{*}{14.526} & \multirow{3}{*}{$0.000^{*}$} \\
\hline & NiTi & 20 & 193.79 & 76.91 & 17.20 & 32.63 & 333.44 & & \\
\hline & TMA & 20 & 259.92 & 70.47 & 15.77 & 139.70 & 337.52 & & \\
\hline \multirow{3}{*}{ Avg. Kinetic friction (gm) } & SS & 20 & 113.10 & 50.43 & 11.28 & 39.77 & 194.76 & \multirow{3}{*}{8.934} & \multirow{3}{*}{$0.000^{*}$} \\
\hline & NiTi & 20 & 162.84 & 52.97 & 11.85 & 74.44 & 250.64 & & \\
\hline & TMA & 20 & 194.37 & 76.99 & 17.21 & 96.46 & 305.91 & & \\
\hline
\end{tabular}

One way ANOVA statistics, *significant at $p<0.05$ 
Table 4: Comparison of static and kinetic frictional forces of stainless steel archwire with different types of brackets

\begin{tabular}{|c|c|c|c|c|}
\hline Frictional force & Archwire & Bracket type & Mean Difference & Sig \\
\hline \multirow{6}{*}{ Static peak (gm) } & \multirow{2}{*}{ SS } & SS & 54.55 & 0.271 \\
\hline & & Self-ligating & 77.39 & 0.077 \\
\hline & \multirow{2}{*}{ SS } & Ceramic & -54.55 & 0.271 \\
\hline & & Self-ligating & 22.84 & 0.791 \\
\hline & \multirow{2}{*}{ SS } & Ceramic & -77.39 & 0.077 \\
\hline & & SS & -22.84 & 0.791 \\
\hline \multirow{6}{*}{ Avg. Kinetic friction (gm) } & \multirow{2}{*}{ SS } & SS & 69.76 & 0.062 \\
\hline & & Self-ligating & 95.01 & $0.007^{*}$ \\
\hline & \multirow{2}{*}{ SS } & Ceramic & -69.76 & 0.062 \\
\hline & & Self-ligating & 25.25 & 0.682 \\
\hline & \multirow{2}{*}{ SS } & Ceramic & -95.01 & $0.007^{*}$ \\
\hline & & SS & -25.25 & 0.682 \\
\hline
\end{tabular}

Table 5: Comparison of static and kinetic frictional forces of NiTi archwire with different types of brackets

\begin{tabular}{|c|c|c|c|c|}
\hline Frictional force & Archwire & Bracket type & Mean Difference & Sig \\
\hline \multirow{6}{*}{ Static peak (gm) } & \multirow{2}{*}{$\mathrm{NiTi}$} & SS & 49.25 & 0.233 \\
\hline & & Self-ligating & 101.46 & $0.003^{*}$ \\
\hline & \multirow{2}{*}{$\mathrm{NiTi}$} & Ceramic & -49.25 & 0.233 \\
\hline & & Self-ligating & 52.20 & 0.196 \\
\hline & \multirow{2}{*}{$\mathrm{NiTi}$} & Ceramic & -101.46 & $0.003^{*}$ \\
\hline & & SS & -52.20 & 0.196 \\
\hline \multirow{6}{*}{ Avg. Kinetic friction (gm) } & \multirow{2}{*}{ NiTi } & SS & 45.08 & 0.097 \\
\hline & & Self-ligating & 121.51 & $0.000 *$ \\
\hline & \multirow{2}{*}{ NiTi } & Ceramic & -45.08 & 0.097 \\
\hline & & Self-ligating & 76.43 & $0.002 *$ \\
\hline & \multirow{2}{*}{$\mathrm{NiTi}$} & Ceramic & -121.51 & $0.000^{*}$ \\
\hline & & SS & -76.43 & $0.002 *$ \\
\hline
\end{tabular}

Table 6: Comparison of static and kinetic frictional force of TMA archwire with different types of brackets

\begin{tabular}{|c|c|c|c|c|}
\hline Frictional force & Archwire & Bracket type & Mean Difference & Sig \\
\hline \multirow{6}{*}{ Static peak (gm) } & \multirow{2}{*}{ TMA } & SS & 43.79 & 0.167 \\
\hline & & Self-ligating & 105.64 & $0.000^{*}$ \\
\hline & \multirow{2}{*}{ TMA } & Ceramic & -43.79 & 0.167 \\
\hline & & Self-ligating & $61.84\left(^{*}\right)$ & 0.032 \\
\hline & \multirow{2}{*}{ TMA } & Ceramic & -105.64 & $0.000^{*}$ \\
\hline & & SS & -61.84 & $0.032 *$ \\
\hline \multirow{6}{*}{ Avg. Kinetic friction (gm) } & \multirow{2}{*}{ TMA } & SS & 41.35 & 0.122 \\
\hline & & Self-ligating & 127.60 & $0.000^{*}$ \\
\hline & \multirow{2}{*}{ TMA } & Ceramic & -41.35 & 0.122 \\
\hline & & Self-ligating & 86.25 & $0.000 *$ \\
\hline & \multirow{2}{*}{ TMA } & Ceramic & -127.60 & $0.000^{*}$ \\
\hline & & SS & -86.25 & $0.000^{*}$ \\
\hline
\end{tabular}


Graph 1 : Static and Kinetic friction of stainless steel bracket with different types of archwire

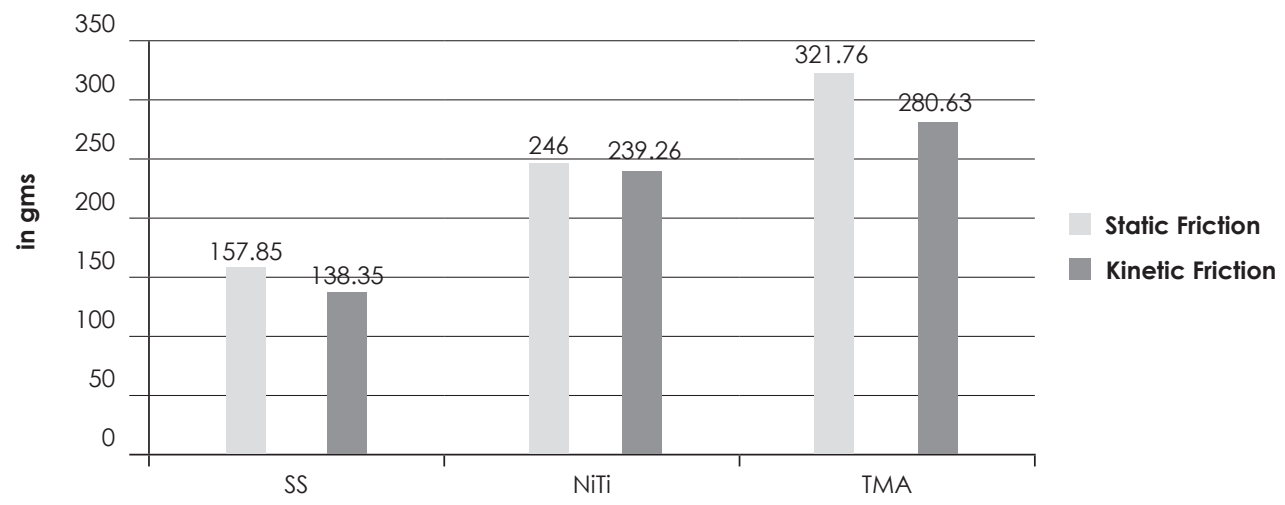

Graph 2 : Static and Kinetic friction of Ceramic bracket with different types of archwire

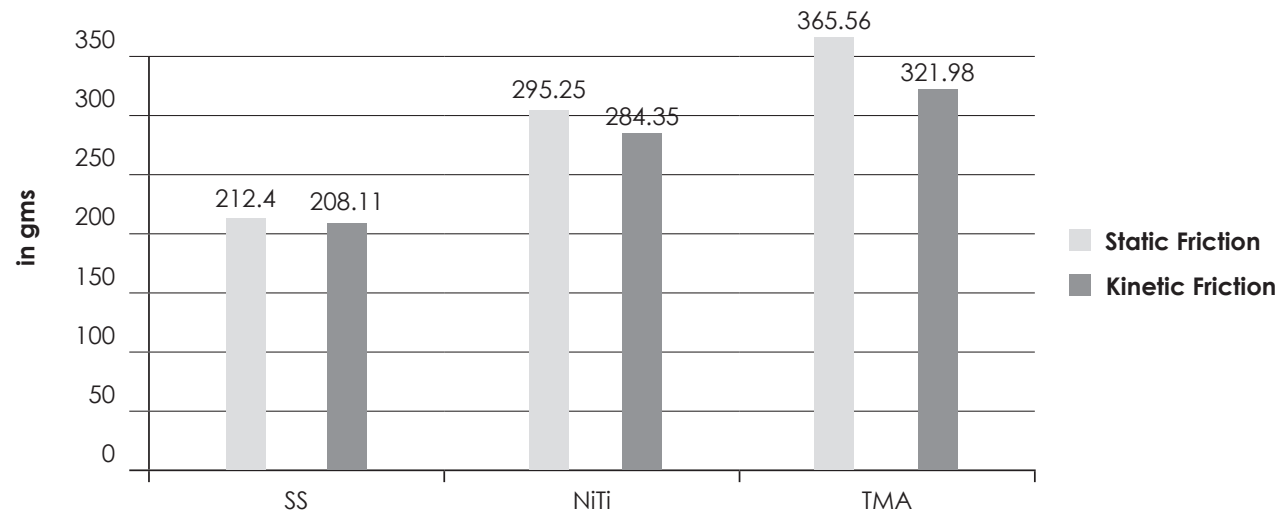

Graph 3 : Static and Kinetic friction of self-ligating bracket with different types of archwire

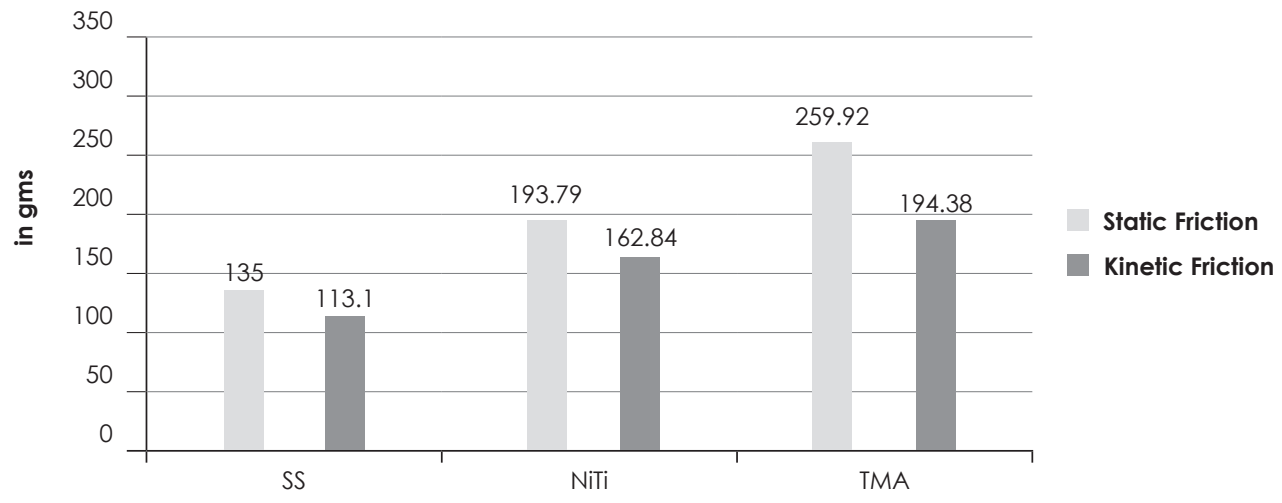




\section{DISCUSSION}

In orthodontic mechanotherapy, a biologic tissue response with resultant tooth movement will occur only when the applied forces adequately overcome the friction at the bracket-wire interface. ${ }^{7}$ It means that the force to move a tooth via a bracket relative to a wire results in friction localized at bracket wire interface that may prevent the attainment of an optimal force in the supporting tissue. Therefore orthodontists need to have a quantitative assessment of the orthodontic forces encountered to achieve precise force level and to obtain an optimal biological response for efficient tooth movement. 8.9

In present study the mean static and kinetic friction value of stainless steel bracket (Gemini) with $0.019 \times 0.025$ " stainless steel wire showed significant result with all types of archwires ( $p<0.05)$ (Table1, Graph 1). When $0.019 \times 0.025$ " ss wire was compared with the same size NiTi and TMA (Table 1); the difference in force required to slide the bracket along the wire increased significantly, with stainless steel requiring the least force and beta titanium requiring the most. These differences were judged to be caused by surface roughness. It appears that stainless steel provides significantly less frictional resistance than NiTi and beta titanium. This report is in accordance with the study of Garner et $a^{10}$ who showed that beta-titanium and NiTi wires resisted sliding in stainless steel brackets more than the stainless steel wires when tested without bracket angulations. The present report is in accordance with the study of Kusy et al " ${ }^{1}$ who stated that stainless steel bracket with stainless steel archwire, which renders the surface chemically passive because of the formation of chromium oxide layer, promotes a lower coefficient of friction than stainless steel bracket with beta-titanium archwire.

It has been reported that the friction resistance (FR) of ceramic brackets is increased by their rough surface conditions. In the present study the mean static and kinetic friction value of ceramic bracket (Clarity) with $0.019 \times 0.025$ " stainless steel archwire showed statistically significant difference with all types of wires $(p<0.05)$ (Table2, Graph 2). In the present study beta-titanium archwires generated higher friction than both stainless steel and nickel-titanium archwires for ceramic bracket-archwire combinations. This is in accordance with the study conducted by Loftus et $\mathrm{al}^{,{ }^{12}}$ and Prososki et $\mathrm{al}, \mathrm{i}^{13}$ they reported that the increased friction with beta-titanium wire could be due to the adherence of wire to the material of bracket slot. Damon self-ligating bracket is a second generation self-ligating bracket which does not exert spring pressure on the archwire. This bracket uses self-ligating archwire cover which slides vertically in occlusal direction in the upper arch and gingival direction in the lower arch.
In the present study the mean static and kinetic friction value of self-ligating brackets (Damon) with $0.019 \times 0.025$ " stainless steel archwire showed statistically significant difference with all types of archwires $(p<0.05)$. So the frictional forces increased in the order of SS, NiTi, and TMA, and there was a significant difference in frictional force between NiTi and TMA wires. (Table3, Graph 3). This is in accordance with study conducted by Kusy et $a^{8}{ }^{8}$ who observed similar trends for stainless steel brackets with these alloys. The high friction associated with TMA wire is attributed to the high titanium content and the surface reactivity that cause adherence during sliding mechanics. Kusy" showed that the surface texture of NiTi wire is rougher than TMA and SS, but frictional characteristics do not follow a similar pattern according to the study conducted by Porosoki. ${ }^{13}$ Previous reports are in the favor of our study, according to which NiTi wire showed higher frictional force than SS wire with self-ligating brackets.

The present in-vitro study showed that self-ligating brackets had significantly lower static and kinetic frictional forces than ceramic and stainless steel bracket in all combinations of archwire alloys. This is in accordance with the study conducted by Loftus ${ }^{12}$ and Shivpuja. ${ }^{14}$ The stainless steel brackets had the lowest frictional force value than ceramic brackets which may be due to the characteristic of the metal which allows better polishing and a smoother surface. The difference of the frictional force values between the ceramic bracket with the metal reinforced slot and the stainless steel brackets can be due to the difficulty in adjusting the metal to the ceramic and to their different expansion coefficients. This is in accordance with the study conducted by Loftus, ${ }^{12} \mathrm{Ho},{ }^{3}$ Downing, ${ }^{4}$ Kusy. ${ }^{8}$

The lowest frictional force generated by self-ligating bracket could be explained by the difference in structural design of bracket body, in addition to the material composition of bracket slot and cap. This is in accordance with the study conducted by Shivapuja. ${ }^{14}$ Another possible reason for low friction with self-ligating bracket might be due to the labial cover which may not contact the archwire and therefore eliminate one source of the normal force caused by the pressure from conventional stainless steel. This is in accordance with the study conducted by Berger et $a l,{ }^{15}$ Sims et $a .^{16}$ By using self-ligating bracket system tends to address two important concerns of orthodontists. A decrease in frictional resistance; both static and dynamic has the benefit on hard and soft tissues, and decrease in treatment time. The self-ligating bracket systems are advantageous as they do not cause poor oral hygiene as with elastomeric ties, and eliminate the chance of lacerations to the patient as well as orthodontist from the use of stainless steel ties. 


\section{CONCLUSION}

Following conclusions are drawn from this study:

1. Self-ligating (Damon) brackets generated significantly lower static and kinetic frictional forces than stainless steel (Gemini) and Ceramic brackets (Clarity).

2. Static frictional force was more than kinetic friction with all archwire-bracket combinations.
3. Among the archwire materials, Beta-titanium showed the highest and stainless steel archwire showed the lowest frictional force.

\section{REFERENCES}

1. Read-Ward GE, Jones SP, Davies EH. A comparison of self-liagting and conventional Orthodontic bracket system. Br J Orthod 1997; 24:309-317

2. Keith O, Jones SP, Davies EH. The influence of bracket material, ligation force and wear on frictional resistance of orthodontic brackets. Br J Orthod 1993; 20:109-15.

3. Ho KS, West VC. Frictional resistance between edgewise brackets and archwires. Aust Orthod J 1991; 100:513-22.

4. Downing A, McCabe JF, Gordon PH. A study of frictional forces between orthodontic brackets and archwires. Br J Orthod 1994; 21:34957.

5. Stannard JG, Gau JM, Hanna M. Comparative friction of orthodontic wires under dry and wet conditions. Am J Orthod Dentofac Orthop 1986; 89:485-91.

6. Tidy DC. Frictional forces in fixed appliances. Am J Orthod Dentofac Orthop 1989; 96:249-54.

7. Angolkar PV, Kapila S, Duncanson MG, Nanda RS. Evaluation of friction between ceramic brackets and orthodontic wires of four alloys. Am J Orthod Dentofac Orthop 1990; 98:499-506.

8. Kusy RP, Whitley JQ, Prewitt MJ. Comparison of the frictional coefficients for selected archwire-bracket slot combinations in the dry and wet states. Angle Orthod 1991; 61:293-302.

9. Ogata RH, Nanda RS, Duncanson MG. Frictional resistances in stainless steel bracket-wire combinations with effects of vertical deflections. Am J Orthod Dentofac Orthop 1996; 109:535-42.

10. Garner LD, Allai WW, Moore BK. A comparison of frictional forces during simulated canine retraction of a continuous edgewise archwire. Am J Orthod Dentofac Orthop 1986; 90:199-203.

11. Kusy RP, Saunders CR. Surface modification methodologies for polycrystalline alumina: Effects on morphology and frictional coefficients. J Mater Sci Mater Med. 1993; 4:422-430.

12. Loftus BP, Artun J, Nicholls Jl, AlonzoTA, Stoner JA. Evaluation of friction during sliding tooth movement in various bracket archwire combinations. Am J Orthod Dentofac Orthop 1999; 116:336-45.

13. Prososki RR, Bagby MD, Erickson LC. Static frictional force and surface roughness of nickel-titanium archwires. Am J Orthod Dentofac Orthop 1991; 100:341-8.

14. Shivapuja PK, Berger J. A comparative study of conventional ligation and self-ligation bracket systems. Am J Orthod Dentofac Orthop 1994; 106:472-80.

15. Berger JL. The influence of the SPEED bracket's self-ligating design on force levels in tooth movement: a comparative in vitro study. Am J Orthod Dentofac Orthop 1990; 97:219-28.

16. Sims AP, Waters NE, Birnie DJ, Pethybridge RJ. A comparison of the forces required to produce tooth movement in vitro using two ligating brackets and a preadjusted bracket employing two types of ligation. Eur J Orthod 1993; 15:377-85. 